\title{
Treatment selection and experience in multiple sclerosis: survey of neurologists
}

\author{
This article was published in the following Dove Press journal: \\ Patient Preference and Adherence \\ 3 April 2014 \\ Number of times this article has been viewed
}

\author{
Kristin A Hanson' \\ Neetu Agashivala ${ }^{2}$ \\ Kathleen W Wyrwich ${ }^{3}$ \\ Karina Raimundo ${ }^{2}$ \\ Edward Kim² \\ David W Brandes ${ }^{4}$ \\ 'UBC: An Express Scripts Company, \\ Dorval, QC, Canada; ${ }^{2}$ Novartis \\ Pharmaceuticals Corporation, \\ East Hanover, NJ, USA; ${ }^{3}$ Evidera, \\ Bethesda, MD, USA; ${ }^{4}$ Hope MS \\ Center, Knoxville, TN, USA
}

Correspondence: Kristin A Hanson Value Demonstration, Safety, Epidemiology, Registries, and Risk Management, UBC: An Express Scripts Company, 185 Dorval Avenue, Suite 500, Dorval, QC, Canada H9S 5J9

Tel +I $514422827 \mid$

Fax + I 5144228272

Email kristy.hanson@ubc.com
Background: Multiple sclerosis (MS) is a complex disease with many therapeutic options. Little is known about how neurologists select particular disease-modifying therapies (DMTs) for their patients.

Objective: To understand how neurologists make decisions regarding the prescription of DMTs for patients with MS, and to explore neurologists' experiences with individual DMTs.

Methods: From December 2012 to January 2013, members of a nationwide physician market research panel were sent an online study invitation with a link to a survey website. Eligible neurologists were included if they currently practice medicine in the United States, and if they treat $\geq 20$ patients with MS.

Results: A total of 102 neurologists ( $n=63$ general neurologists; $n=39$ MS specialists; $81.4 \%$ male) completed the survey. The mean (standard deviation) number of years in practice since completing medical training was 16.4 (8.6) years. Overall, the most commonly prescribed DMTs were subcutaneous interferon (IFN) $\beta$-1a and glatiramer acetate; approximately $5.5 \%$ of patients were untreated. The most important attributes of DMT medication selection were (in order of importance) efficacy, safety, tolerability, patient preference, and convenience. The DMT with the highest neurologist-reported percentage of patients who were "Very/Extremely Satisfied" with their therapy was fingolimod (31.0\%), followed by glatiramer acetate $(13.9 \% ; P=0.017)$. Compared with fingolimod $(94.0 \%)$, significantly fewer $(P<0.05)$ neurologists reported that "All/Most" of their patients were adherent to treatment with glatiramer acetate $(78.0 \%)$, subcutaneous IFN $\beta$-1a (84.0\%), and IFN $\beta$-1b (75.0\%); no significant differences were observed with intramuscular IFN $\beta$-1a $(92.9 \% ; P=0.75)$. Patients' calls to neurologists' offices were most commonly related to side effects for all self-injectable DMTs, whereas calls about fingolimod primarily involved insurance coverage issues.

Conclusion: Our survey results showed that very few patients with MS did not received any DMT. Among the DMTs available at the time of the survey, neurologists reported that patients were most satisfied with, and adherent to, fingolimod, but these patients also faced more problems with insurance coverage when compared with those taking self-injectable DMTs.

Keywords: multiple sclerosis, disease-modifying therapy, physician survey, treatment selection, treatment adherence, treatment satisfaction

\section{Introduction}

Multiple sclerosis (MS) is a chronic inflammatory disorder of the central nervous system leading to both physical and cognitive impairments. ${ }^{1}$ Currently, there is no cure for this degenerative disease. Approximately 400,000 people in the United States, and 2.1 million worldwide, are affected by MS, with $\sim 85 \%$ of patients with MS being initially diagnosed with the relapsing-remitting MS subtype. ${ }^{2}$ The relapsing-remitting 
MS subtype is characterized by clearly defined attacks of worsening neurologic function (relapses), which are followed by partial or complete recovery periods (remissions), during which symptoms improve. ${ }^{2}$ Clinical manifestations and the course of relapsing MS are highly variable among patients, but most patients develop disability over time due to incomplete recovery and/or progressive disease. ${ }^{3}$

The primary treatment goals for MS include slowing disease progression, decreasing the frequency of relapses, managing symptoms, and maintaining or improving patients' health-related quality of life. Currently, there are ten Food and Drug Administration (FDA)-approved disease-modifying therapies (DMTs) available for the treatment of MS. Selfinjectable agents include glatiramer acetate, intramuscular (IM) interferon (IFN) $\beta$-1a, subcutaneous (SC) IFN $\beta$-1a, and IFN $\beta$-1b (Betaseron $^{\circledR}$; Bayer AG, Leverkusen, Germany; and Extavia $^{\circledR}$; Novartis AG, Basel, Switzerland). Natalizumab and mitoxantrone are both administered through intravenous infusion. Within the past few years, three oral DMTs have been FDA-approved and have entered the market. Fingolimod was the first oral DMT approved (2010), and has the most real-world experience; teriflunomide and dimethyl fumarate were approved in 2012 and 2013, respectively.

Although randomized, double-blind, placebo-controlled trials have demonstrated that DMTs reduce the frequency and severity of MS relapses, there is a lack of consensus among international treatment guidelines regarding the selection of DMTs. ${ }^{4}$ Furthermore, there is a need for updated treatment guidelines that evaluate the use of oral DMTs, as the most recent guidelines were published prior to the availability of oral agents in the market. ${ }^{5}$

Despite satisfactory efficacy of the DMTs, several studies have shown that patients are not persistent with DMTs. A recent systematic review showed that for the self-injectable DMTs (glatiramer acetate and the IFNs), discontinuation rates ranged from $17 \%-36 \%{ }^{6}$ The main reasons for discontinuing therapy included the development of adverse events and a lack of treatment efficacy. In addition, the psychological and physical factors associated with regular injections (for example, anxiety, injection phobia, and injection of the site reactions) may adversely impact medication adherence, and these factors have been commonly observed in both randomized controlled trials and in observational studies. ${ }^{6}$ Given these reasons, it has been hypothesized that oral DMTs are a promising alternative for patients who adhere poorly to intravenous or self-injectable DMTs. A recent analysis of administrative claims from a large pharmacy benefits management company in the US showed that patients initiating fingolimod therapy demonstrated higher levels of treatment adherence and persistence, as measured by the medication possession ratio $(>=0.8)$, the proportion of days covered $(>=0.8)$, and time to discontinuation, when compared to patients initiating one of the first-line self-injectable DMTs (IFN $\beta$-1b, IFN $\beta$-1a, or glatiramer acetate)., ${ }^{7,8}$

To date, there have been no published data describing DMT selection and neurologists' perceptions of individual DMTs. The present survey study was designed to address these knowledge gaps in the current medical literature. When the survey was developed, fingolimod was the only oral DMT available on the market for the treatment of MS; therefore, discussions around oral DMTs should not be extrapolated to DMTs that were not included in the survey.

\section{Methods \\ Study design}

A cross-sectional, web-based survey was fielded from December 2012 to January 2013. The study protocol was approved by a central Institutional Review Board (Ethical and Independent Review Services, Corte Madera, CA, USA). A market research panel was used to recruit approximately 100 neurologists as survey respondents. The study participants were blinded to the name of the study sponsor in order to minimize biased responses. Respondents were classified as general neurologists (where $<40 \%$ of patients treated have a diagnosis of MS) or MS specialists (where $\geq 40 \%$ of patients treated have a diagnosis of MS). The ratio of general neurologists to MS specialists was prespecified to be approximately $3: 2$.

\section{Participants}

All study participants met the following study eligibility criteria: $\geq 18$ years of age; able to read English; living in the United States; currently treating a minimum of 20 patients with MS; and were either practicing as a general neurologist or as an MS specialist, as defined in the previous section. In addition, all respondents were required to provide informed consent prior to completing the survey.

Potential respondents were sent an email invitation that described the purpose of the study and contained a direct link to the survey website. Upon entering the website, the respondents provided their informed consent electronically, and they answered screening questions. Respondents who met the study's eligibility criteria were allowed to proceed to and complete the survey. 


\section{Measures}

\section{Survey development}

The Web-based survey was designed specifically for this study, and it was developed to capture information about the neurologists' choice of DMT for the treatment of MS. It was also designed to capture the neurologists' perceptions about individual first-line DMTs. The survey questions were designed based on the results of a brief, targeted literature review, as well as on a consultation with an MS clinical expert (DWB). A draft survey was pilot-tested with two neurologists before it was finalized.

\section{Survey content}

Respondents were asked questions regarding their prescribing behaviors and their ranking of medication attributes that were considered during the DMT selection process. To assess neurologists' experiences with individual DMTs in routine clinical practice, the neurologists were asked about each first-line DMT that they currently prescribe (based on their responses to the first survey question). They were asked questions on: 1) perceived patient adherence; 2) perceived patient satisfaction; 3) the frequency of medication-related calls received from patients during the first year of treatment; and 4) the most common reasons for calling. The survey took approximately 15 minutes to complete.

The medications evaluated in the survey included the following first-line DMTs: glatiramer acetate; IM IFN $\beta$-1a; SC IFN $\beta$-1a; IFN $\beta$-1b (Betaseron ${ }^{\circledR}$ and Extavia ${ }^{\circledR}$ ); and fingolimod. At the time the survey was developed, teriflunomide and dimethyl fumarate were not yet approved for the indication of MS and, therefore, these medications were not included in the survey. Although Betaseron ${ }^{\circledR}$ and Extavia $^{\circledR}$ are both IFN $\beta-1 b$, the survey questions were asked using the following format: brand name (generic name). Therefore, responses were collected for Betaseron ${ }^{\circledR}$ and Extavia $^{\circledR}$, individually.

\section{Statistical analyses}

Descriptive statistics were used to summarize all of the variables, including the number of observations and the mean (standard deviation) or the median (range) for the continuous variables. The frequencies (proportion) of categorical variables were computed where applicable.

Since Betaseron ${ }^{\circledR}$ and Extavia ${ }^{\circledR}$ are made with the same formulation of IFN $\beta-1 b$, but are commercialized by different manufacturers, the results for each brand were combined into an IFN $\beta$-1b group in the study analysis. Cases where physicians responded differently to these two brand name medications were noted and further examined.

Post hoc analyses were conducted to compare neurologists' perceptions of individual DMTs. Fingolimod was selected as the comparator since it was the only oral DMT among the treatments studied. To facilitate the treatment satisfaction and treatment adherence analyses, some categories were collapsed. The treatment satisfaction responses, which were initially provided on a 7-point Likert-type scale with responses ranging from "Extremely Dissatisfied" to "Extremely Satisfied", were collapsed into the following three categories: "Dissatisfied" (which included "Extremely Dissatisfied", "Very Dissatisfied", and "Dissatisfied"); "Satisfied" (which included "Somewhat Satisfied" and "Satisfied"); and "Very/ Extremely Satisfied" (which included "Very Satisfied" and "Extremely Satisfied"). Treatment adherence responses were provided on a 5-point Likert-type scale, with responses ranging from "All or Nearly All" to "None." With no participants responding "None", the responses were reduced to the following two categories: "All/Most" (which included "All or Nearly All" and "Most"); and "Some/Few" (which included "Some" and "Few"). Wilcoxon and chi-square tests were used for comparisons of ordinal and nominal categorical variables, respectively.

Exploratory analyses were conducted to see if there was a difference in responses among general neurologists and MS specialists. Student's $t$-tests were used to compare continuous variables, and chi-square tests were used to compare categorical variables. All analyses were performed using SAS $^{\circledR}$ statistical software version 9.1.3 (SAS Institute Inc, Cary, NC, USA).

\section{Results}

A total of 253 neurologists were screened; 102 were eligible to participate and completed the survey ( $\mathrm{n}=63$ [general neurologists]; $n=39$ [MS specialists]). Participants were excluded from the study for one or more of the following reasons: general neurologist quota already met $(n=93)$; not providing informed consent $(\mathrm{n}=46)$; not meeting other study inclusion/exclusion criteria (for example, treating $>20$ patients with MS; $n=23$ ); and duplicate responders $(n=12)$. In the analytic sample, more than $80 \%$ of respondents were male with a mean age of $49.6( \pm 10.6)$ years, and they had been practicing medicine for an average of $16.4( \pm 8.6)$ years after completing relevant medical training (Table 1). Overall, nearly half of the respondents $(48.1 \%)$ worked in a single-specialty practice, and $28.4 \%$ 
Table I Sociodemographic characteristics

\begin{tabular}{|c|c|c|c|}
\hline Characteristics & $\begin{array}{l}\text { General neurologists } \\
N=63\end{array}$ & $\begin{array}{l}\text { MS specialists } \\
N=39\end{array}$ & $\begin{array}{l}\text { All neurologists } \\
\mathrm{N}=102\end{array}$ \\
\hline \multicolumn{4}{|l|}{ Age } \\
\hline Mean (SD) & $50.2(11.0)$ & $48.6(10.0)$ & $49.6(10.6)$ \\
\hline Median (minimum-maximum) & $49(20-88)$ & $47(33-75)$ & $48(20-88)$ \\
\hline \multicolumn{4}{|l|}{ Sex, n (\%) } \\
\hline Male & $52(82.5 \%)$ & 31 (79.5\%) & $83(81.4 \%)$ \\
\hline Female & $\mathrm{II}(\mathrm{I7.5 \% )}$ & $8(20.5 \%)$ & $19(18.6 \%)$ \\
\hline \multicolumn{4}{|l|}{ Race/ethnicity, n (\%) } \\
\hline American Indian or Alaska Native & $0(0.0 \%)$ & $\mathrm{I}(2.6 \%)$ & $\mathrm{I}(\mathrm{l} .0 \%)$ \\
\hline Asian & $\mathrm{II}(17.5 \%)$ & II (28.2\%) & $22(21.6 \%)$ \\
\hline Black or African American & $0(0.0 \%)$ & $0(0.0 \%)$ & $0(0.0 \%)$ \\
\hline Hispanic or Latino & $3(4.8 \%)$ & I (2.6\%) & $4(3.9 \%)$ \\
\hline Native Hawaiian or other Pacific Islander & $0(0.0 \%)$ & $0(0.0 \%)$ & $0(0.0 \%)$ \\
\hline White & 49 (77.8\%) & $25(64.1 \%)$ & $74(72.5 \%)$ \\
\hline Other & $0(0.0 \%)$ & $\mathrm{I}(2.6 \%)$ & $\mathrm{I}(\mathrm{I} .0 \%)$ \\
\hline \multicolumn{4}{|l|}{ Years in practice after completing all medical training } \\
\hline Mean $(S D)$ & $17.3(8.7)$ & I5.I (8.2) & $16.4(8.6)$ \\
\hline Median (minimum-maximum) & $17(3-35)$ & $14(2-35)$ & $15(2-35)$ \\
\hline \multicolumn{4}{|l|}{ Location of medical school, n (\%) } \\
\hline US & 50 (79.4\%) & 34 (87.2\%) & $84(82.4 \%)$ \\
\hline Other & $13(20.6 \%)$ & $5(12.8 \%)$ & $18(17.6 \%)$ \\
\hline \multicolumn{4}{|l|}{ Type of training, ${ }^{a} n(\%)$} \\
\hline General neurology training & $59(93.7 \%)$ & $30(76.9 \%)$ & $89(87.3 \%)$ \\
\hline MS fellowship & $\mathrm{I}(\mathrm{I} .6 \%)$ & $24(61.5 \%)$ & $25(24.5 \%)$ \\
\hline Other fellowship & $14(22.2 \%)$ & $5(12.8 \%)$ & $19(18.6 \%)$ \\
\hline \multicolumn{4}{|l|}{ Type of practice setting, n (\%) } \\
\hline Private single specialty office (MS specialty center) & $3(4.8 \%)$ & $9(23.1 \%)$ & $12(11.8 \%)$ \\
\hline Private single specialty office (non-MS specialty) & $31(49.2 \%)$ & $6(15.4 \%)$ & 37 (36.3\%) \\
\hline Private multispecialty & $15(23.8 \%)$ & $3(7.7 \%)$ & $18(17.6 \%)$ \\
\hline Academic & $9(14.3 \%)$ & $20(51.3 \%)$ & 29 (28.4\%) \\
\hline Community hospital & $5(7.9 \%)$ & I $(2.6 \%)$ & $6(5.9 \%)$ \\
\hline
\end{tabular}

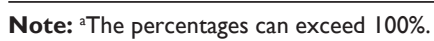

Abbreviations: $\mathrm{N}$, total population; MS, multiple sclerosis; SD, standard deviation; $\mathrm{n}$, sample population.

practiced in academic settings. The sociodemographic characteristics of the general neurologists were not significantly different from the MS specialists, with the exception of their primary practice setting and the medical training received. The majority of MS specialists (51.9\%) worked in an academic setting, while the most common practice setting for general neurologists was a private, single-specialty office.

\section{General MS practice questions}

In decreasing order of significance, the most important attributes in selecting a DMT for a treatment-naïve patient were as follows: efficacy; safety; tolerability; patient preference; and convenience. Most neurologists (86.3\%) ranked "efficacy" as the most important attribute. The most commonly-reported events that would influence the neurologist's decision to switch from one DMT to another were frequency of relapse (95.1\%), worsening structural change in the brain, as indicated by magnetic resonance imaging scan (74.5\%); and worsening disability without relapse (72.5\%). Overall, $59.8 \%$ of neurologists reported that all three events were important.

\section{DMT prescribing behavior}

Overall, the most commonly prescribed DMTs were glatiramer acetate, SC IFN $\beta-1 \mathrm{a}$, and IM IFN $\beta$-1a (Figure 1). The self-injectable DMTs (glatiramer acetate, IM IFN $\beta$-1a, SC IFN $\beta$-1a, and IFN $\beta$-1b) were more commonly prescribed than fingolimod, as $90.2 \%-97.1 \%$ of respondents reported having at least one patient who was currently being treated with a self-injectable DMT, while $85.3 \%$ of respondents indicated that at least one patient was currently being treated with fingolimod.

Approximately one-fourth (24.5\%) of neurologists reported prescribing "other" medications, including teriflunomide (6.9\%), mitoxantrone (5.9\%), methotrexate, mycophenolate mofetil, azathioprine, cyclophosphamide, rituximab, and 


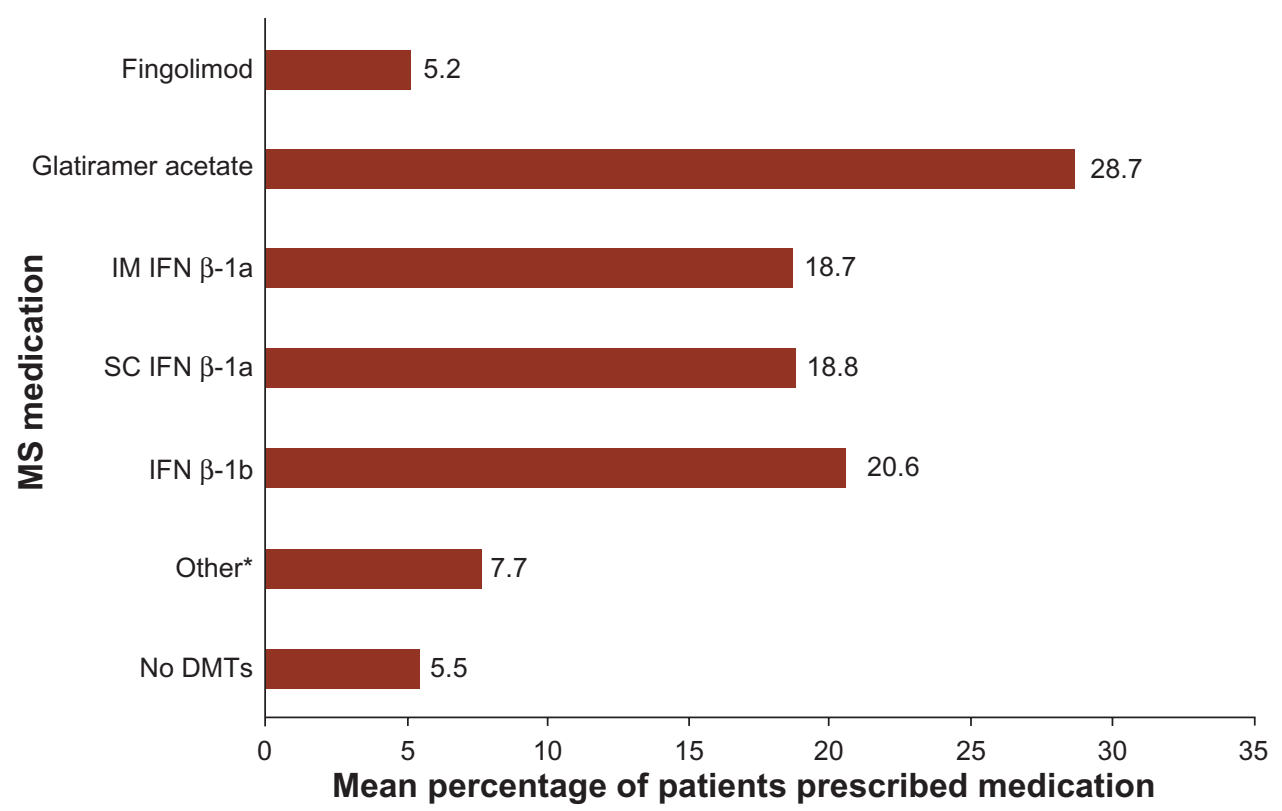

Figure I Mean percentage of patients prescribed individual DMTs, as reported by neurologists.

Note: *Includes patients on natalimumab (6.6\%) and other medications (azathioprine, cladribine, cyclophosphamide, daclizumab, intravenous immunoglobulin, methotrexate, mycophenolate mofetil, naltrexone, rituximab, corticosteroids, teriflunimide [1.1\% combined]).

Abbreviations: MS, multiple sclerosis; IM, intramuscular; IFN, interferon; SC, subcutaneous; DMTs, disease-modifying therapies.

corticosteroids (each $<5.0 \%$ ). Overall, approximately 5.5\% of the neurologists' patients with MS were estimated to be untreated, with individual neurologists reporting that $0.0 \%$ $23.0 \%$ of patients were not currently on therapy for MS.

There were no significant differences in prescribing behavior observed among general neurologists and MS specialists. Differences in the mean reported percentage of patients using each of the first-line DMTs ranged from $0.0 \%$ (fingolimod: $5.2 \%$ utilization reported by both MS specialists and general neurologists) to $3.2 \%$ (IFN $\beta-1 \mathrm{~b}: 13.5 \%$ versus $16.7 \%$ reported by MS specialists and general neurologists, respectively). The reported mean percentage of patients who were not receiving a DMT was slightly greater among MS specialists $(6.8 \%)$ than general neurologists $(4.6 \%)$.

\section{Neurologist-reported patient treatment adherence and satisfaction}

Overall, neurologists reported high levels of perceived treatment adherence, which was defined as patients taking $\geq 80 \%$ of their scheduled doses. Nearly all of the respondents reported that they thought "All/Most" of their patients were highly adherent with fingolimod and IM IFN $\beta$-1a $(94.0 \%$ and $92.9 \%$, respectively; $P=0.7500$ ). However, compared with fingolimod, significantly fewer neurologists reported that "All/Most" of their patients were adherent with glatiramer acetate $(78.0 \% ; P=0.0170)$, SC IFN $\beta-1 \mathrm{a}(84.0 \% ; P=0.0350)$, and IFN $\beta-1 \mathrm{~b}(75.0 \% ; P=0.0006)$.
Overall, $>90 \%$ of respondents reported that they believed their patients were at least "Somewhat Satisfied" with their current MS therapy. Among the DMTs, neurologists reported that patients were the most satisfied with fingolimod, as 31.0\% of neurologists reported that their patients were "Very Satisfied" or "Extremely Satisfied" with their treatment. Compared to fingolimod, the satisfaction rates were significantly lower for all of the other first-line DMTs (Table 2).

\section{Neurologist office calls related to individual DMTs}

The median reported percentage of patients calling their neurologist's office during the first year of DMT use was $25.0 \%$. The median number of calls made to the neurologist's office during the first year of treatment was three for fingolimod and two for all other DMTs.

Most neurologists (range: $59.0 \%-83.3 \%$ ) reported that "side effects" were the primary reason for patients' calls about the self-injectable DMTs (Table 3). In contrast, only $26.8 \%$ of neurologists reported that "side effects" were the primary reason for calls about fingolimod. The most common primary reason listed for fingolimod-related calls, as reported by $41.5 \%$ of neurologists, was "insurance coverage."

\section{Discussion}

This cross-sectional survey of prescribing neurologists describes the priorities and perceptions of clinicians treating 
Table 2 Neurologists' perceptions of patient satisfaction and adherence with treatment: comparison with fingolimod

\begin{tabular}{|c|c|c|c|c|c|c|c|c|c|}
\hline & \multirow{3}{*}{$\frac{\text { Fingolimod }}{\mathbf{N}(\%)}$} & \multicolumn{2}{|c|}{ IM IFN $\beta$-Ia } & \multirow{2}{*}{\multicolumn{2}{|c|}{$\begin{array}{l}\text { IFN } \beta \text {-Ib } \\
\left(\text { Betaseron }^{\circledR} / \text { Extavia }^{\circledR}\right)\end{array}$}} & \multicolumn{2}{|c|}{ Glatiramer acetate } & \multicolumn{2}{|c|}{ SC IFN $\beta$-I a } \\
\hline & & \multirow[t]{2}{*}{$\mathbf{N}(\%)$} & \multirow[t]{2}{*}{$P$-value } & & & \multirow[t]{2}{*}{$\mathbf{N}(\%)$} & \multirow[t]{2}{*}{$P$-value } & \multirow[t]{2}{*}{$\mathbf{N}(\%)$} & \multirow[t]{2}{*}{$P$-value } \\
\hline & & & & $\mathbf{N}(\%)$ & $P$-value & & & & \\
\hline Patient satisfaction, $\mathrm{N}^{\mathrm{a}}$ & 87 & 99 & & 92 & & 101 & & 96 & \\
\hline Dissatisfied & $5(5.7 \%)$ & $6(6.1 \%)$ & 0.0006 & $3(3.3 \%)$ & 0.0007 & $5(5.0 \%)$ & 0.017 & $3(3.1 \%)$ & 0.0020 \\
\hline Satisfied & $55(63.2 \%)$ & $85(85.9 \%)$ & & $83(90.2 \%)$ & & $82(81.2 \%)$ & & $85(88.5 \%)$ & \\
\hline Very/extremely satisfied & 27 (31.0\%) & $8(8.1 \%)$ & & $6(6.5 \%)$ & & $14(13.9 \%)$ & & $8(8.3 \%)$ & \\
\hline Patient adherence, $\mathrm{N}^{\mathrm{a}, \mathrm{b}}$ & 84 & 98 & & 88 & & 100 & & 94 & \\
\hline All/most & 79 (94.0\%) & 91 (92.9\%) & 0.75 & $66(75.0 \%)$ & 0.0006 & $78(78.0 \%)$ & 0.0022 & 79 (84.0\%) & 0.035 \\
\hline Some/few & $5(6.0 \%)$ & $7(7.1 \%)$ & & $22(25.0 \%)$ & & $22(22.0 \%)$ & & $15(16.0 \%)$ & \\
\hline
\end{tabular}

Notes: ${ }^{\top}$ The number of neurologists prescribing the medication; 'bexcludes neurologists reporting “I don't know.” Betaseron ${ }^{\circledR}$; Bayer AG, Leverkusen, Germany. Extavia ${ }^{\circledR}$; Novartis AG, Basel, Switzerland.

Abbreviations: $\mathrm{N}$, number; IM, intramuscular; IFN, interferon; SC, subcutaneous.

MS, and how their treatment choices impact their clinical experiences with individual first-line DMTs. In our survey, neurologists reported on the most important attributes in selecting a DMT for a treatment-naïve patient; in decreasing order of importance, these attributes included efficacy, safety, tolerability, patient preference, and convenience. These results are consistent with the recommendations of a recent Delphi panel, which stated that health plans should consider a treatment's efficacy, effectiveness, and safety, as well as the patient's preference. ${ }^{9}$

Approximately $5.5 \%$ of the surveyed neurologists' patients were not receiving any medications for MS, with individual neurologists reporting that $0 \%-23 \%$ of patients in their practices were not being treated. Although the reasons why these patients with MS were not receiving medications were not explored in this survey, possible explanations included patient preference, relatively mild disease activity, and high-cost sharing or other aspects of pharmacy benefit design. ${ }^{10-12}$

Exploratory analyses were conducted to assess whether survey responses varied by physician type. The only statistically significant differences in baseline characteristics that were observed between the general neurologists and the MS specialists were their practice settings and the types of training received. No remarkable differences in responses were found between general neurologists and MS specialists with regard to their prescribing behaviors and their experiences with individual DMTs. However, it should be noted that this was an exploratory analysis, and the study was not powered to detect these group differences. Additional research with a larger sample size should be conducted to further explore the possible differences in treatment selection and in the experiences of individual DMTs, as reported by general neurologists and MS specialists.

Side effects were reported as the primary reason why patients called the neurologist's office during the patients' first year of DMT use for all self-injectable medications. This finding is consistent with previous reports, which noted that side effects are the main reason for patients' dissatisfaction in treatment, which can lead to the discontinuation of selfinjectable DMTs. ${ }^{6,13-16}$ This finding may, at least partially, explain why neurologists perceived that a significantly greater proportion of fingolimod users (31.0\%) were "Very/ Extremely Satisfied" with their DMT, as compared to patients using self-injectable DMTs (range: $3.0 \%-13.9 \%$ ).

Table 3 Callers' reasons for calling neurologists' offices: comparison with fingolimod

\begin{tabular}{|c|c|c|c|c|c|c|c|c|c|}
\hline \multirow[t]{3}{*}{ Call reason } & \multirow{3}{*}{$\frac{\text { Fingolimod }}{\mathrm{N}=82}$} & \multicolumn{2}{|c|}{ IM IFN $\beta$-I a } & \multirow{2}{*}{\multicolumn{2}{|c|}{$\begin{array}{l}\text { IFN } \beta \text {-Ib } \\
\left(\text { Betaseron }^{\circledR} / \text { Extavia }^{\circledR}\right)\end{array}$}} & \multicolumn{2}{|c|}{ Glatiramer acetate } & \multicolumn{2}{|c|}{ SC IFN $\beta$-I a } \\
\hline & & \multirow[t]{2}{*}{$N=99$} & \multirow[t]{2}{*}{$P$-value } & & & \multirow[t]{2}{*}{$\mathrm{N}=100$} & \multirow[t]{2}{*}{$P$-value } & \multirow[t]{2}{*}{$\mathrm{N}=96$} & \multirow[t]{2}{*}{$P$-value } \\
\hline & & & & $N=84$ & $P$-value & & & & \\
\hline Obtain medical & $15(18.3 \%)$ & $10(10.1 \%)$ & $<0.0001$ & 7 (8.3\%) & $<0.0001$ & $16(16.0 \%)$ & 0.0002 & 7 (7.3\%) & $<0.0001$ \\
\hline \multicolumn{10}{|l|}{ information } \\
\hline Side effects & 22 (26.8\%) & 81 (8I.8\%) & & 70 (83.3\%) & & 59 (59.0\%) & & $80(83.3 \%)$ & \\
\hline Insurance coverage & 34 (4I.5\%) & $5(5.1 \%)$ & & $5(6.0 \%)$ & & $16(16.0 \%)$ & & $4(4.2 \%)$ & \\
\hline Financial assistance & $5(6.1 \%)$ & $0(0.0 \%)$ & & $0(0.0 \%)$ & & $5(5.0 \%)$ & & $2(2.1 \%)$ & \\
\hline Other & $6(7.3 \%)$ & $3(3.0 \%)$ & & $2(2.4 \%)$ & & $4(4.0 \%)$ & & $3(3.1 \%)$ & \\
\hline
\end{tabular}

Notes: Betaseron ${ }^{\circledast}$; Bayer AG, Leverkusen, Germany. Extavia ${ }^{\circledR}$; Novartis AG, Basel, Switzerland.

Abbreviations: N, number; IM, intramuscular; IFN, interferon; SC, subcutaneous. 
Medication adherence is important in MS. An administrative claims analysis of patients with MS who received a self-injectable DMT was conducted by Tan et al. ${ }^{14}$ The study demonstrated that compared with patients who adhere to treatment as closely as possible, patients with poor treatment adherence were significantly more likely to have MS-related hospitalizations and MS relapses, as well as higher medical costs. ${ }^{14}$ Although the Tan et al ${ }^{14}$ study was conducted prior to the launch of oral DMTs, a similar correlation is expected between medication adherence and MS-related outcomes with the use of oral DMTs; however, additional research is needed to confirm this hypothesis. The results of the present survey showed that glatiramer acetate is the most commonly prescribed first-line DMT, but it also had the second-lowest reported level of perceived treatment adherence. IM IFN $\beta$-1a and fingolimod had the highest perceived level of treatment adherence, potentially due to their once weekly and oral route of administration, respectively. This is consistent with the results of a US administrative claims data study, which demonstrated higher adherence rates in patients using fingolimod when compared to those using self-injected DMTs. ${ }^{7,8}$

In October 2013, real-world results from the MSBase study - a global, longitudinal, observational registry for MS - as well as US administrative claims data showed that fingolimod reduced the annualized relapse rate and risk of relapse by around $50 \%$ when compared to INFs or glatiramer acetate. ${ }^{17-19}$ Although medication adherence was not directly assessed in this study, it potentially played a role in improved medication effectiveness. Furthermore, the impact of the MSBase study's findings on physicians' perceptions of DMTs, as well as physicians' prescribing behaviors, are unknown.

The present study was designed to collect data on DMT selection in clinical practice, and on neurologists' perceptions of individual first-line DMTs. However, there are several limitations to this study that should be noted. First, since this was a cross-sectional survey, treatment effects, changes in prescribing behaviors, and neurologists' perceptions of DMTs over time were not measured, nor was patients' actual medication adherence. Second, the scope of the survey was limited, leaving some questions unanswered. For example, respondents were not asked to provide reasons as to why some of their patients with MS were not currently treated with any MS medications, and we did not explore whether medication prescribing behaviors varied by MS subtype. Also, neurologists' experience with the newest FDA-approved DMTs (teriflunomide and dimethyl fumarate) and second- line DMTs (for example, natalizumab or mitoxantrone) were not assessed in the survey. Finally, the survey was conducted only in the US, and the results may not be generalizable in other regions with different health care and reimbursement systems and practices. Furthermore, although a nationwide research panel was used to recruit physician respondents, it is hypothesized that panelist members may be more treatmententhusiastic than the general population of neurologists and the geographic region of the sample was not collected in the survey.

\section{Conclusion}

Neurologists demonstrated clear criteria for initiating, selecting, and switching DMTs, with efficacy (as measured by relapse frequency) being the most important factor. Neurologists believed that their patients were generally satisfied with, and adherent to, their current DMT, and that patients who were prescribed fingolimod had higher levels of treatment satisfaction and adherence than those prescribed self-injectable DMTs. The most common reason why patients called their neurologist about fingolimod involved insurance coverage issues, suggesting that neurologists' clinical decision making may increasingly come into conflict with payer priorities in the treatment of MS.

\section{Disclosure}

This study was funded by Novartis Pharmaceuticals Corporation, East Hanover, NJ, USA. KAH and KWW are employees of UBC and Evidera, respectively, which received funding for this research from Novartis. NA and EK are employees of Novartis. KR was a research fellow at Novartis while the research was being conducted. DWB serves on advisory panels for the following companies: Biogen Idec, Teva, Novartis, Genzyme, Sanofi, Acordia; serves on speaking panels for the following: Biogen Idec, Teva, Novartis, Genzyme, Acorda, Questcor, Avanir; and receives research support from Biogen Idec and Teva. The authors report no other conflicts of interest in this work.

\section{References}

1. Girouard N, Soucy N. Patient considerations in the management of multiple sclerosis: development and clinical utility of oral agents. Patient Prefer Adherence. 2011:101-108.

2. National Multiple Sclerosis Society [webpage on the Internet]. Fact sheet: multiple sclerosis. New York, NY: National Multiple Sclerosis Society; 2012. Available from: http://www.nationalmssociety.org/chapters/ $\mathrm{mnm} / \mathrm{mediacenter} /$ factsheetmultiplesclerosis/index.aspx. Accessed October 18, 2012

3. Tullman MJ. Overview of the epidemiology, diagnosis, and disease progression associated with multiple sclerosis. Am J Manag Care. 2013;19(Suppl 2):S15-S20. 
4. Trisolini MG [webpage on the Internet]. Comparison of multiple sclerosis guidelines underscores need for collaboration. Rockville, MD: Agency for Healthcare Research and Quality; 2008 [updated December 8, 2008]. Available from: http://guideline.gov/expert/expertcommentary.aspx?id=16443. Accessed March 1, 2013.

5. Goodin DS, Frohman EM, Garmany GP, Jr, et al. Disease modifying therapies in multiple sclerosis: report of the Therapeutics and Technology Assessment Subcommittee of the American Academy of Neurology and the MS Councit for Clinical Practice Guidelines. Neurology. 2002;58:169-178.

6. Giovannoni G, Southam E, Waubant E. Systematic review of diseasemodifying therapies to assess unmet needs in multiple sclerosis: tolerability and adherence. Mult Scler. 2012;18(7):932-946.

7. Agashivala $\mathrm{N}, \mathrm{Wu} \mathrm{N}$, Abouzaid $\mathrm{S}$, et al. Compliance to fingolimod and other disease modifying treatments in multiple sclerosis patients, a retrospective cohort study. BMC Neurology. 2013;13:138. doi: 10.1186/1471-2377-13-138.

8. Agashivala N, Wu N, Wu Y, Kim E, Boulanger L, Brandes D. Comparison of time to discontinuation among multiple sclerosis patients receiving fingolimod and other first-line disease-modifying treatments. Proceedings of the European Committee for Research and Treatment in Multiple Sclerosis (ECTRIMS) Congress; October 10-13, 2012; Lyon, France.

9. Miller RM, Happe LE, Meyer KL, Spear RJ. Approaches to the management of agents used for the treatment of multiple sclerosis: consensus statements from a panel of US managed care pharmacists and physicians. J Manag Care Pharm. 2012;18(1):54-62.

10. Pittock SJ, Weinshenker BG, Noseworthy JH, et al. Not every patient with multiple sclerosis should be treated at time of diagnosis. Arch Neurol. 2006;63(4):611-614.

11. Roach ES. Early multiple sclerosis: to treat or not to treat? Arch Neurol. 2006;63(4):619.
12. Romley J, Goldman D, Eber M, Dastani H, Kim E, Raparla S. Cost-sharing and initiation of disease-modifying therapy for multiple sclerosis. Am J Manag Care. 2012;18(8):460-464.

13. Steinberg SC, Faris RJ, Chang CF, Chan A, Tankersley MA. Impact of adherence to interferons in the treatment of multiple sclerosis: a nonexperimental, retrospective, cohort study. Clin Drug Investig. 2010; 30(2):89-100

14. Tan H, Cai Q, Agarwal S, Stephenson JJ, Kamat S. Impact of adherence to disease-modifying therapies on clinical and economic outcomes among patients with multiple sclerosis. Adv Ther. 2011;28(1):51-61.

15. Treadaway K, Cutter G, Salter A, et al. Factors that influence adherence with disease-modifying therapy in MS. J Neurol. 2009;256(4): $568-576$.

16. Twork S, Nippert I, Scherer P, Haas J, Pöhlau D, Kugler J. Immunomodulating drugs in multiple sclerosis: compliance, satisfaction and adverse effects evaluation in a German multiple sclerosis population. Curr Med Res Opin. 2007;23(6):1209-1215.

17. Spelman T, Bergvall N, Tomic D, et al. Real-world comparative effectiveness of fingolimod and interferon/glatiramer therapies in a switch population using propensity-matched data from MSBase. Proceedings of the 29th Congress of the European Committee for Treatment and Research in Multiple Sclerosis (ECTRIMS); October 2-5, 2013; Copenhagen, Denmark.

18. Bergvall N, Makin C, Lahoz R, et al. Relapse rates in patients with multiple sclerosis switching from interferon to fingolimod or glatiramer acetate: a US claims database study. PLoS One. 2014;9(2):e88472. doi: 10.1371/journal.pone.0088472.

19. Bergvall N, Makin C, Lahoz R, et al. Comparative effectiveness of fingolimod versus interferons or glatiramer acetate for relapse rates in multiple sclerosis: a retrospective US claims database analysis. Curr Med Res Opin. 2013;29(12):1647-1656.
Patient Preference and Adherence

\section{Publish your work in this journal}

Patient Preference and Adherence is an international, peer-reviewed, open access journal focusing on the growing importance of patient preference and adherence throughout the therapeutic continuum. Patient satisfaction, acceptability, quality of life, compliance, persistence and their role in developing new therapeutic modalities and compounds to

\section{Dovepress}

optimize clinical outcomes for existing disease states are major areas of interest. This journal has been accepted for indexing on PubMed Central. The manuscript management system is completely online and includes a very quick and fair peer-review system. Visit http://www.dovepress.com/ testimonials.php to read real quotes from published authors. 